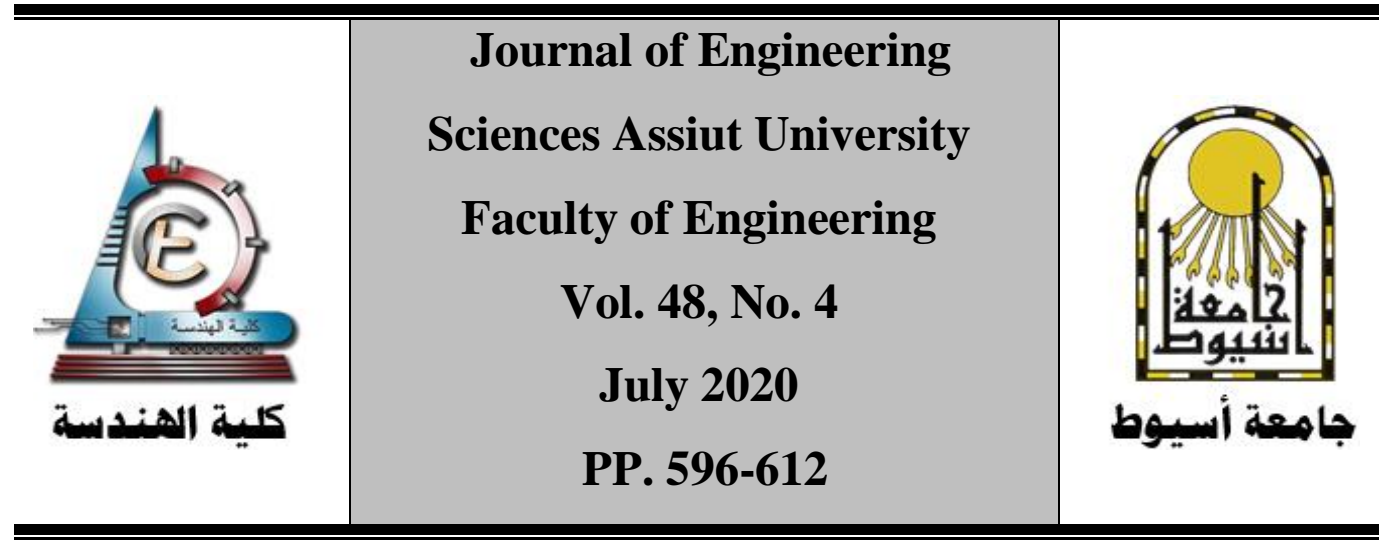

\title{
GREY WOLF OPTIMIZATION APPROACH-BASED EXHAUST TEMPERATURE CONTROL FOR GAS TURBINE POWER SYSTEM
}

\author{
Hany. F. S. Abu-Seada 1, Mohamed M.M. Slama², Mohamed A. M. \\ Hassan $^{3}$, M. A. Ebrahim 4

\begin{tabular}{c}
\hline Cairo North Power Station, Ministry of Electricity, Cairo, Egypt. \\
hanyabuseada@gmail.com \\
${ }^{2}$ Electrical Power Department, Faculty of Engineering, Benha University, \\
Kaliobeya.Egypt. \\
dr_moenes1@yahoo.com \\
${ }^{3}$ Electrical Power Department, Faculty of Engineering, Cairo University, Giza, \\
Egypt, mmustafa@eng.cu.edu.eg \\
${ }^{4}$ Electrical Power Department, Faculty of Engineering, Benha University, \\
Kaliobeya, Egypt \\
mohamed.mohamed@feng.bu.edu.eg, mohamedahmed_en@yahoo.com \\
Received Revised ; Accepted
\end{tabular}

\begin{abstract}
Gas turbines are one of the most important power generation technologies in countries especially with natural gas resources. However, its complicated technology and the operation of which at peak performance is effective in power generation systems. This paper proposes the use of grey wolf optimization (GWO) approach in optimizing the proportional integral derivative (PID) controller parameters using MATLAB program to control the exhaust temperature of a gas turbine. The main aim is to keep on turbine operation behavior at optimum performance. The achieved results show the effectiveness of the proposed exhaust temperature controller based on the use of the Rowen's model, clearly approach for the gas turbine. The obtained results of the optimum values of the GWO algorithm are compared with those attained using the optimum values of the current $265 \mathrm{MW}$ simple cycle, Actual single-shaft HDGT.
\end{abstract}


Hany.F. S. Abu-Seada, Grey Wolf Optimization Approach-based exhaust temperature....

KEYWORDS: Grey wolf optimization (GWO), proportional integral derivative (PID), Combined Cycle Power Plant (CCPP), optimal control, load disturbances, Heavy-duty gas turbine (HDGT), fuel stroke ratio (FSR).

\section{Introduction}

Power system control and stability problems constitute essential considerations in the planning, design, operation, and control of modern power systems. During the past decade, where power generation has subjected to several extremely significant changes, the growth in interconnections and the use of new technologies lead the complexity of power systems to increase continually [1]. These include deregulation of the electricity industry around the world, with a greater focus on economic and financial concerns instead of purely engineering issues. On the other hand, coinciding with this, environmental issues and interest increasing in it are leading to an estimation of existing greenhouse gas emissions and the utilization of renewable energy sources. In addition, advances in computer technology, numerical analysis, control theory, and equipment modeling have contributed to develop and improve analytical tools and better system-design procedures [1].

Gas turbine-based power plants are one of the new economical and efficient means of power generation. In the past 40 years, gas turbines have established growing service in the power and petrochemical industries. Gas Turbine Technology has seen an observable development in the last 20 years. The growth is achieved by the growing of materials technology, new coatings, and new cooling methods. In the same time of increasing the compressor pressure ratio the gas turbine thermal efficiency increased from about 15 to over 45 percent, which is suitable for power plants. In the past, significant coal and nuclear power plants considered the popular choice for generating the electric power. At present, natural gas-fired turbines have many features like black start capabilities, higher efficiencies, reduction of capital costs, shorter times of installation, the best emission characteristics, and abundance of natural gas supplies that make it the predominant method in power generation field. Figure.1 indicates the cycle of an Industrial Heavy-Duty Gas Turbine (HDGT) [2]. Recently, experimental and few theoretical studies were carried out to examine the strengthening of RC beams with (FRCM). Experimental and theoretical flexural analysis of RC beams strengthened with a cement based high strength composite material was studied by Luciano Ombres, [1]. The As, FSR (fuel stroke ratio), WF (fuel flow), TRGD (turbine generation direction) Now, gas turbines are usually used in many applications. The major application areas of gas turbines are: 
- Aircraft propulsion.

- Generation of Electric power.

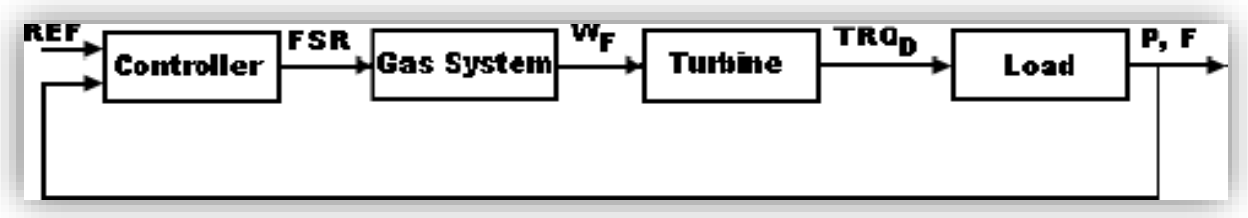

Fig.(1)Simplified Schematic of the Gas Turbine System

In the field of electric power generation, typical uses include stationary power generation plants and mobile power generation engines as ships and aircraft. The term "Combined Cycle Power Plant (CCPP)" describes the combination between gas turbine generators with heat recovery steam generator (HRSG) and steam turbine generator as a method of electric power production. During the last decades, the generation system of combined cycle has developed to increase the efficiency and their low emissions also, reduced natural gas cost. The gas turbine controller has a modular installation and can be acclimatized to a variety of conditions, like the case of gas turbines in simple-cycle, in combined-cycle operation also, the gas turbine fuel cases as in single-fuel or dual-fuel operation. Figure 2 shows in principle the structure of the gas turbine controller. For more clarification, Figure 3 presents a schematic diagram for the gas turbine control as reported in Fig (2), but from a different perspective [1].

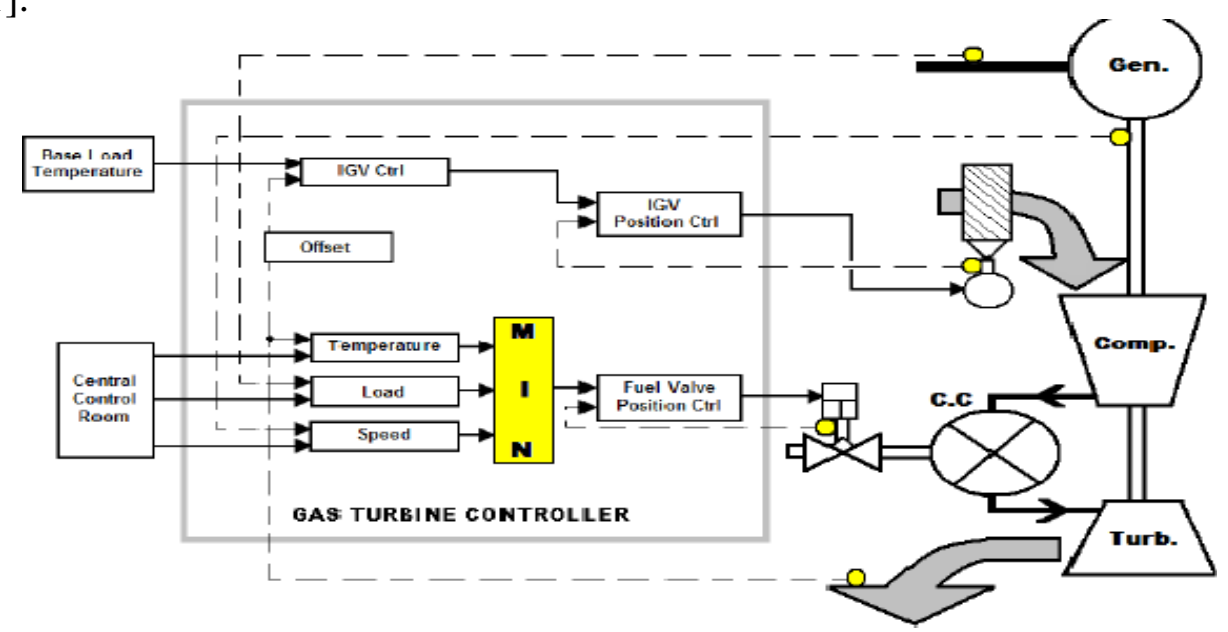

Fig. (2) Gas Turbine Controller Implementation [1]

The performance of a GT is commonly estimated according to its thermal efficiency, specific fuel consumption, work ratio, and power output. Not only that but, several other parameters like the pressure ratio, combustion inlet temperature, ambient temperature, and turbine inlet temperature can affect on 
the performance of a GTPP. [2] Several gas turbines modeling is based on different models. Among these models:

- Rowen's Model,

- Frequency-Dependent (FD) model,

- Vournas's model, IEEE model,

- GGOV1 model and

- CIGRE model.

- Rowen's and Vournas's model will be discussed briefly.

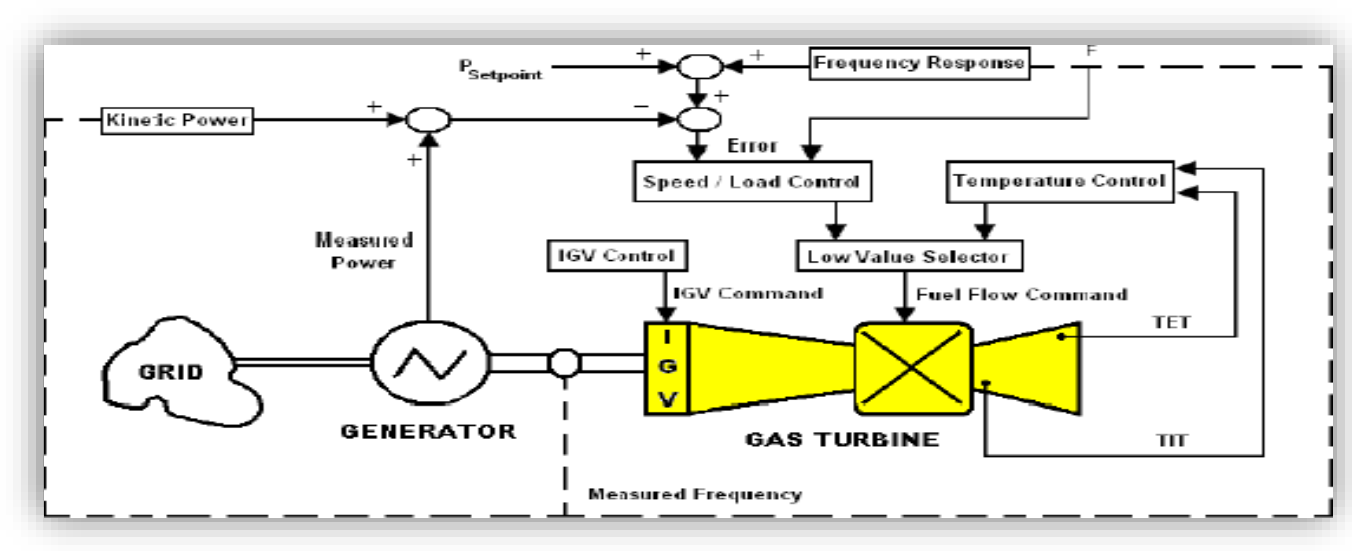

Fig. (3) Gas Turbine (GT) Control Scheme [1]

\section{Rowen's Model}

W. I. Rowen improved a model for gas turbine which can be applied to study the dynamic performance [3].The steady-state characteristics of any gas turbine thermodynamics can be given by a group of algebraic equations which also describe the simple time delays and a few related controls, including the temperature control, governor, and acceleration control consists of Rowen's model. The effects of the governor on system operation can be investigated by using this model. In 1992, Rowen developed the original model to add the system of IGVs and their effect on the gas turbine dynamics, especially the exhaust temperature as shown in Fig. (4). The developed Rowen's model makes modeling of a gas turbine operation installed as part of a CCGT to be more accurate [4]. So, this model is considered the focal point for the development of most CCGT models in last year's [5],[6].

As shown in Fig (5), Dynamics of the gas turbine in Rowen model is mostly made of the function blocks F1 and F2, and simple time delays. There is a transport delay related to gases in the turbine and exhaust system (ETD) and this is included before any temperature calculations. The temperature of the exhaust gases from the turbine is then determined as an output for block F1. 
The characteristics of $\mathrm{F} 1$ can be supposed as a linearly based on speed (N) and fuel flow (WF). A short time delay is also incorporated in the fuel system to consider the time delay associated with the combustion reaction (ECR). The torque in the turbine is then calculated using block F2. In the restricted operating range of this model, the gas turbine torque (TRQD) is linear with respect to fuel flow and turbine speed. The gas turbine mechanical power output (PMG) is the product of the torque and the speed.

An additional first-order lag associated with the compressor discharge volume (TCD) is incorporated before the turbine torque is calculated. Terminologies used throughout the block diagrams are kept in the per-unit system, except for temperatures. As illustrated in [1], Rowen's model is based on that It is a massive duty gas turbine, simple cycle, single-shaft, generator drive only. The speed is allowable in the range of 95 to 107 percent of rated speed. At the conditions of open Inlet Guide Vanes (IGV) only and no Heat Recovery Steam Generator (HRSG) the ISO conditions are, TA $=15 \mathrm{oC}, \mathrm{PA}=101.325 \mathrm{kpa}$. A significant assumption modification had been adopted in [3] (Rowen-II), where the gas turbine had been provided with improved IGVs and which is a part of a CCPP. It is easy to know the two main function blocks in Rowen's models, such that block F1 to calculate the exhaust temperature (TX) .The block F2 is used to calculate the output torque of the gas turbine (TRQD). The governing equations for each block are described below [7, 8].

$$
T_{X}=T_{R}-700\left(1-W_{F}\right)+550(1-N)
$$

Where, $T_{R}$ Turbine rated exhaust temperature. $W_{F}$ Mass fuel flow (pu). N Turbine rotor speed (pu). The governing equation of $\boldsymbol{F}_{2}$ is given as $[3,9,10]$ :

$$
T R Q_{D}=1.3\left(W_{F}-0.23\right)+0.5(1-N)
$$

The governing equation of $\mathrm{F} 3$ is given as $[9,11]$

$$
\mathrm{W}_{\mathrm{X}}=\mathrm{N} \frac{519}{\mathrm{~T} A+460}(\text { Ligv })^{0.257}
$$

Where, $\boldsymbol{L} \boldsymbol{i g} \boldsymbol{v}$ Inlet guide vane position, pu. $\boldsymbol{T}_{\boldsymbol{A}}$ Ambient temperature, ${ }^{\circ} \mathrm{F}$.

\section{Case Study of 265 MW HDGT}

A $265 \mathrm{MW}$ simple cycle, single-shaft HDGT and its available operational and performance data are shown and analyzed for elicitation the parameters of Rowen's model for HDGT. Table (1) shows the official data of the selected 
Hany.F. S. Abu-Seada, Grey Wolf Optimization Approach-based exhaust temperature....

HDGT for modeling. For land-based engines, performance data are extremely inverted at the single point standard conditions. These standard conditions used by the gas turbine industry are:

- Ambient temperature (TA) $15 \mathrm{oC} / 59 \mathrm{oF}$.

- Ambient pressure (PA) 1.013 bar / 14.7 psia.

- Relative humidity $(\Phi) 60 \%$.

These conditions are decided according to the International Standards Organization (ISO) and often indicated to as ISO conditions [2, 12, 13, 14].

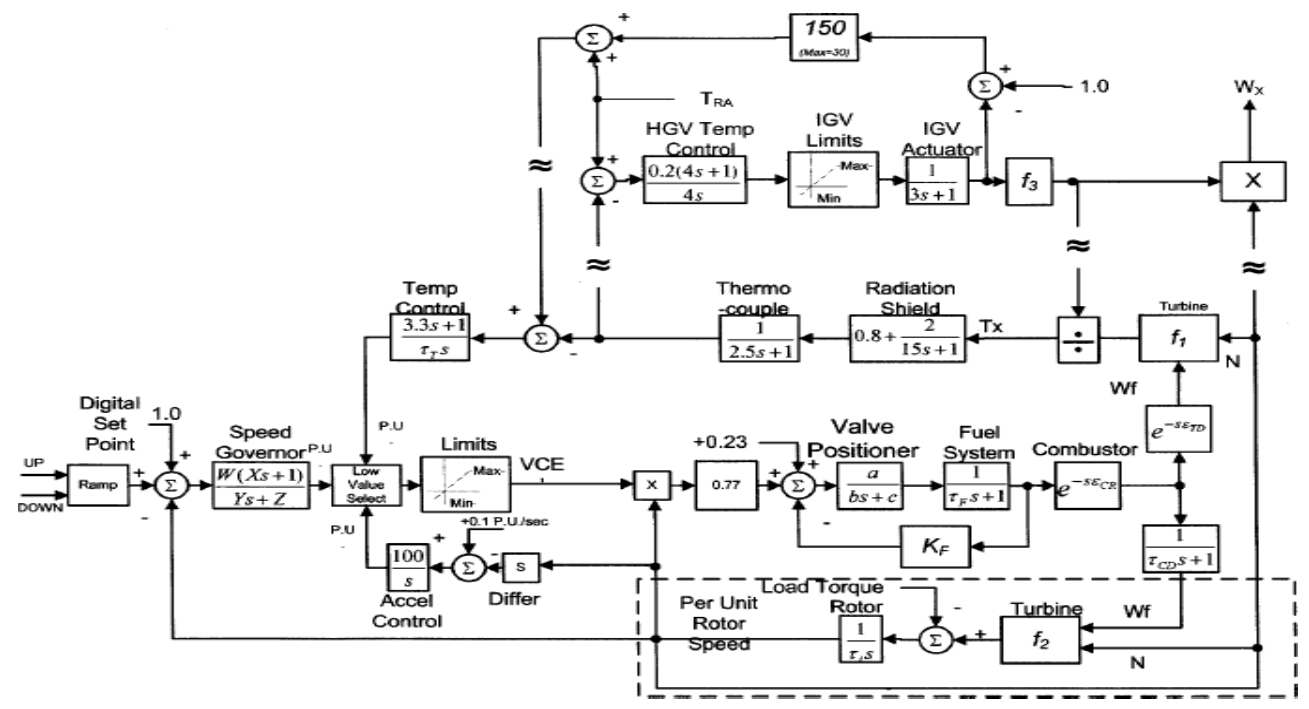

Fig (4) Rowen's Model with IGV [3, 11]

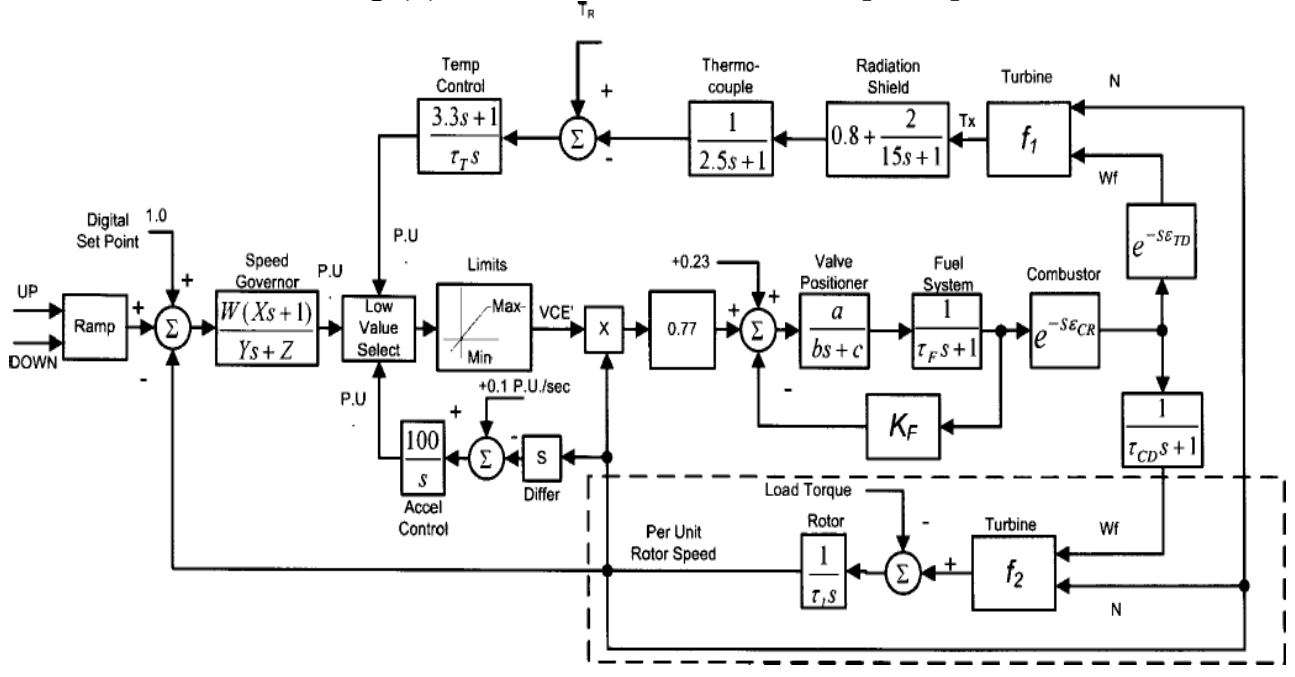

Fig (5): Rowen's Model [3, 11] 
Table [1]: Design Specifications of an Actual Single-Shaft HDGT [14]

\begin{tabular}{|c|c|c|c|}
\hline Parameter & Symbol & Unit & Value \\
\hline Electrical power & PGT & $\mathrm{MW}$ & 265.4 \\
\hline Nominal frequency & $\mathrm{F}$ & $\mathrm{Hz}$ & 50 \\
\hline Turbine speed & $\mathrm{N}$ & $\mathrm{rpm}$ & 3000 \\
\hline Cycle efficiency (simple cycle) & $\eta$ & $\%$ & 38.49 \\
\hline Cycle efficiency (combined cycle) & $\eta$ combined & $\%$ & $\sim 58$ \\
\hline Compressor type & \multicolumn{3}{|c|}{17 -stages axial } \\
\hline Compressor pressure ratio & CPR & bar & 17.29 \\
\hline Compressor inlet air mass flow & WA & $\mathrm{kg} / \mathrm{sec}$ & 651.1 \\
\hline Combustor type & \multicolumn{3}{|c|}{ Annular } \\
\hline Primary operating fuel & Natural gas \\
\hline Fuel mass flow & $\mathrm{kg} / \mathrm{sec}$ & 13.9 \\
\hline The lower heating value of fuel & LHV & $\mathrm{kJ} / \mathrm{kg}$ & 50012 \\
\hline Turbine type & 4-stages axial \\
\hline Turbine diffuser exhaust mass flow & WX & $\mathrm{kg} / \mathrm{sec}$ & 664.8 \\
\hline $\begin{array}{c}\text { Turbine diffuser exhaust temperature (set } \\
\text { point) }\end{array}$ & TET & oC & 585.6 \\
\hline
\end{tabular}

As shown in Fig (6), the values of the frequency-load and temperature control blocks are based on [2], for simulation purposes. The range of the typical values which are usually used for HDGT dynamic models and all obtained values of the controller's parameters are given in $[3,6,14,9]$. A proportional integral derivative (PID) controller will be used to control the exhaust temperature of a gas turbine alternative to the existing temperature control system (PI controller) of HDGT.

\section{PID Controller Parameters Specifications}

To construct the complex automation systems used for power generation, transportation, and manufacturing PID controller is predominantly Merged with logic, alternative functions, selectors, and simple function blocks. Its widespread application is a result to its simple structure and durable implementation over a wide range of operating conditions. The PID control signal is given by the following equation [15]:

$$
u(t)=k_{p}\left(e(t)+\frac{1}{T_{i}} \int_{0}^{t} e(\tau) d \tau+T_{d} \frac{d e(t)}{d t}\right)
$$


Which $u(t)$ expresses the control signal in the equation and $e(t)$ is the system error, which is considered the difference between the desired controlled set point and the measured variable. The control parameters are the proportional gain $(\mathrm{Kp})$, the integral time (Ti) and the derivative time (Td).

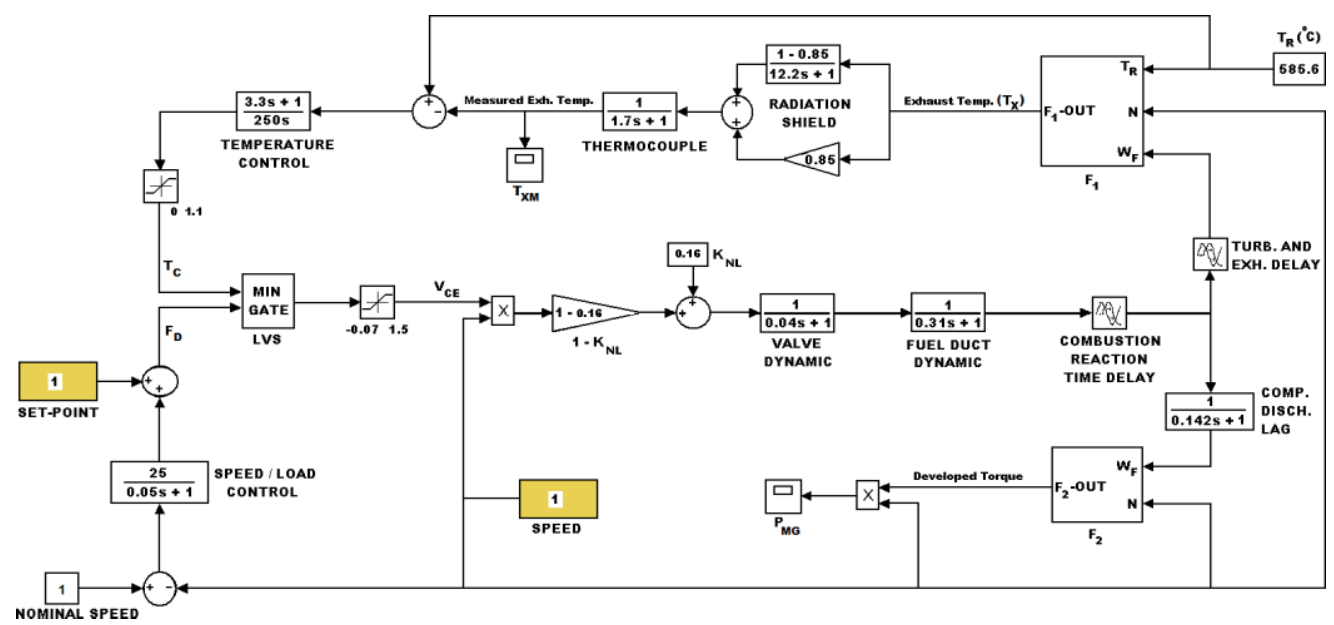

Fig (6): 265MW HDGT Model for Dynamic Studies

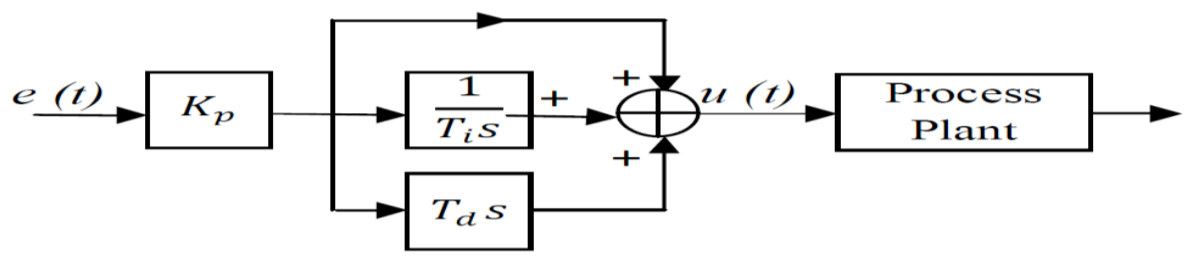

Fig (7) PID Controller block diagram [15].

The effect of $(\mathrm{Kp})$ is appeared in reducing the steady-state error by increasing the value of gain, but cannot eliminate the error. Other effect of $(\mathrm{Kp})$ is reducing the rise time. The function of integral gain $(\mathrm{Ki}=\mathrm{Kp} / \mathrm{Ti})$ is eliminating the steady-state error by reducing the value of (Ti) but this action increases the tendency for oscillation also. The derivative gain $(\mathrm{Kd}=\mathrm{Kp}$.Td) gives the effect of increasing the stability of the system, reduces the overshoot as well as improves the settling time. The main purpose of tuning the PID controller is determination of its parameters $(\mathrm{Kp}, \mathrm{Ki}, \mathrm{Kd})$ which expresses the specification and robustness of the closed-loop and control loop performance over a wide range of operating conditions. 


\section{GWO Algorithm}

The GWO is a meta-heuristic algorithm proposed by Mir Jalili et al. [16] in 2014, which imitates the social manners of grey wolves. These wolves live in a group contains 5-12 members. In this group, the strict dominance hierarchy is practiced where the group has a leader named alpha $(\alpha)$, supported by secondary ones named beta $(\beta)$, which aid $\alpha$ in decision-making. The rest members of the group are named $\delta$ and $\omega$ as shown in Fig (8)

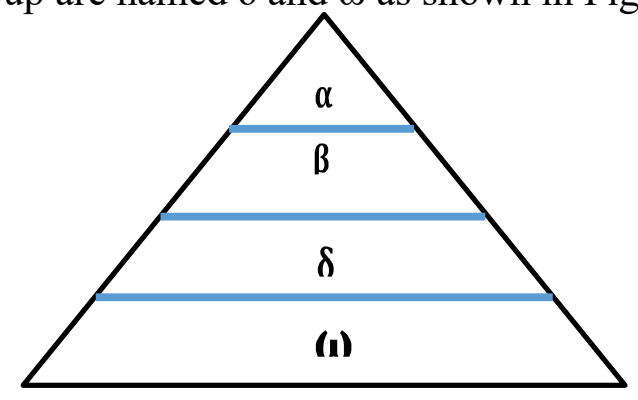

Fig (8) Grey wolf hierarchy

The procedure of hunting the food by the grey wolves is looking for the food, surrounding the food, hunting, and attacking the food. The arithmetic model of surrounding the food is written as follows [17]:

$$
\begin{aligned}
& \vec{D}=\left|\vec{C} \cdot \overrightarrow{X_{P l}}-\overrightarrow{X_{l}}\right| \\
& \vec{X}_{i+1}=\vec{X}_{P i}-\vec{A} \cdot \vec{D}
\end{aligned}
$$

Where $\mathrm{Xi}$ is the place of the grey wolf, $\mathrm{Xpi}$ is the place of the food, D is the distance, $\mathrm{A}$ and $\mathrm{C}$ are vectors calculated as following [16]:

$$
\begin{aligned}
& \vec{a}=2-2 \times t / \text { Max_iter } \\
& \vec{A}=2 \vec{a} \cdot \vec{r}_{1}-\vec{a} \\
& \vec{C}=2 \cdot \vec{r}_{2}
\end{aligned}
$$

$\mathrm{r} 1$ and $\mathrm{r} 2$ are considered as random numbers with the range from (0) to (1). The parameter is a variable that is linearly reduced from 2 to 0 , while the iterations increased. The process of looking for the food position (exploration) could be attained by diverging the search objects when $|A|>1$. The procedure of getting the food (exploitation) could be attained by the convergence of the search entities when $|A|<1$. An entity leads the hunting with $\beta$ and $\delta$ entities support as in (10)-(12) [16]. Fig (9) shows the flowchart of the GWO algorithm. Like other meta-heuristic algorithms, The GWO algorithm can be 
Hany.F. S. Abu-Seada, Grey Wolf Optimization Approach-based exhaust temperature....

disposed to stagnate in a local minimum but the parameters $\mathrm{A}$ and $\mathrm{C}$ can help the GWO algorithm to avoid stagnation.

$$
\begin{gathered}
\vec{D}_{\alpha}=\left|\vec{C}_{1} \cdot \vec{X}_{\propto i}-\vec{X}_{i}\right|, \vec{D}_{\beta}=\left|\vec{C}_{2} \cdot \vec{X}_{\beta i}-\vec{X}_{i}\right| \quad \vec{D}_{\delta}=\left|\vec{C}_{3} \cdot \vec{X}_{\delta i}-\vec{X}_{i}\right| \\
\vec{X}_{1}=\vec{X}_{\propto i}-\vec{A}_{1} \cdot \vec{D}_{\propto} \quad \vec{X}_{2}=\vec{X}_{\beta i}-\vec{A}_{2} \cdot \vec{D}_{\beta} \quad \vec{X}_{3}=\vec{X}_{\delta i}-\vec{A}_{3} \cdot \vec{D}_{\delta} \\
\vec{X}_{i+1}=\frac{\vec{X}_{1}+\vec{X}_{2}+\vec{X}_{3}}{3}
\end{gathered}
$$

Where, a, A1.A2.A3 calculated vectors for the place of the grey wolf.

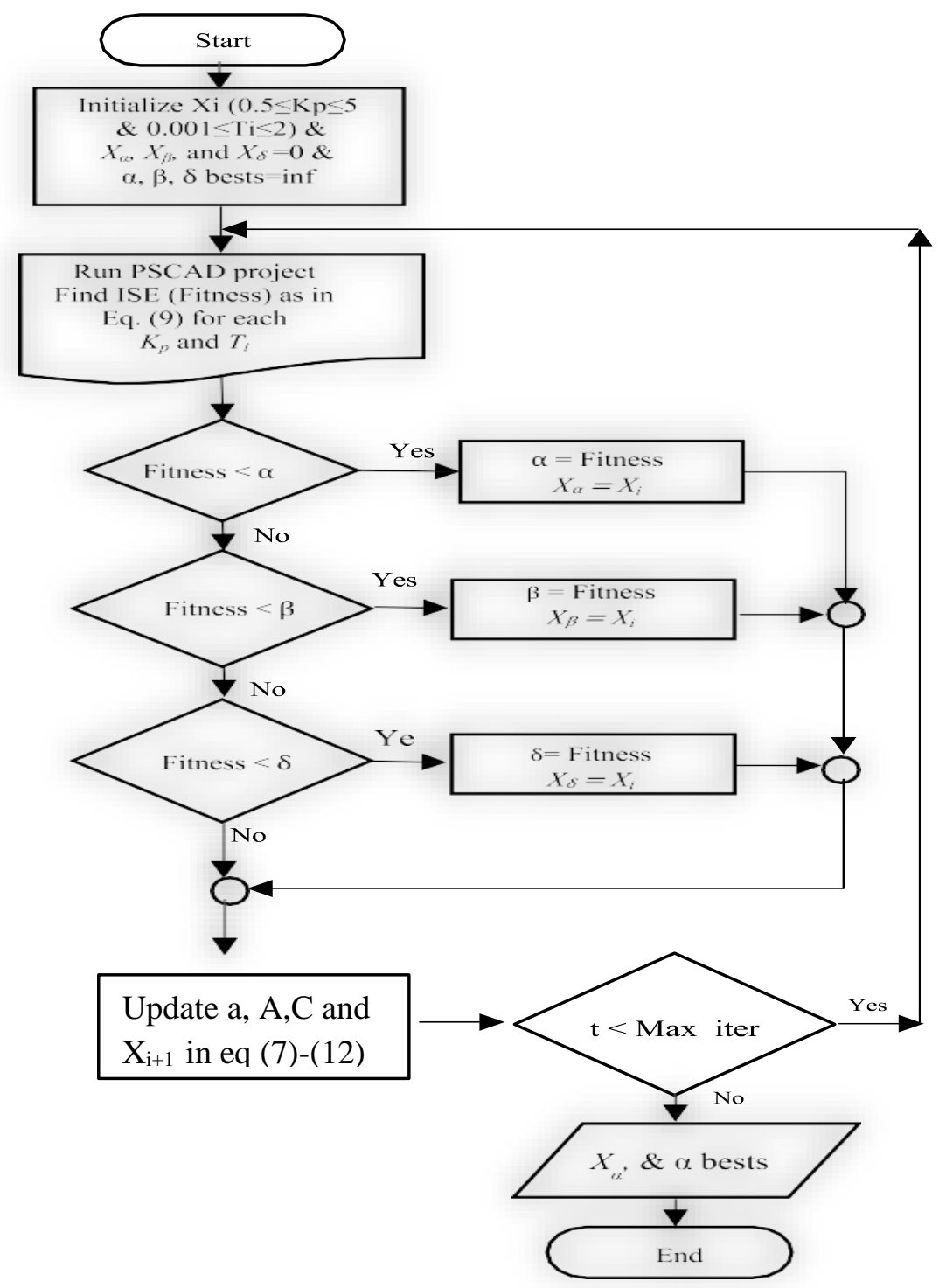

Fig (9). Flowchart of the GWO Algorithm [16]. 


\section{Results and Discussion}

Here, the performances of the GWO-PID and the existing temperature control system (PI controller) of HDGT in controlling the exhaust temperature of a gas turbine are compared. The performance criteria used in evaluating the PID controller parameters in the GWO tuning method are the ITSE, ISE, ITAE, IAE. Then the parameters which achieved the best performance are selected to be the tuning parameters of the PID controller. The performance criterion of ITSE is the best according to the lowest overshoot and shortest rise time, so the parameters of PID (KP, KI, KD) controller, which evaluated by using that performance criterion.

\subsection{CASE (1): Sudden Additional Load Effect}

To compare between the behavior of GWO-PID and existing temperature control system (PI controller) of HDGT a disturbance of increasing the exhaust temperature above the rated value is assumed, as the load of the turbine will increase suddenly by $20 \%$ above the rated MW value according to the power network load and frequency changes.

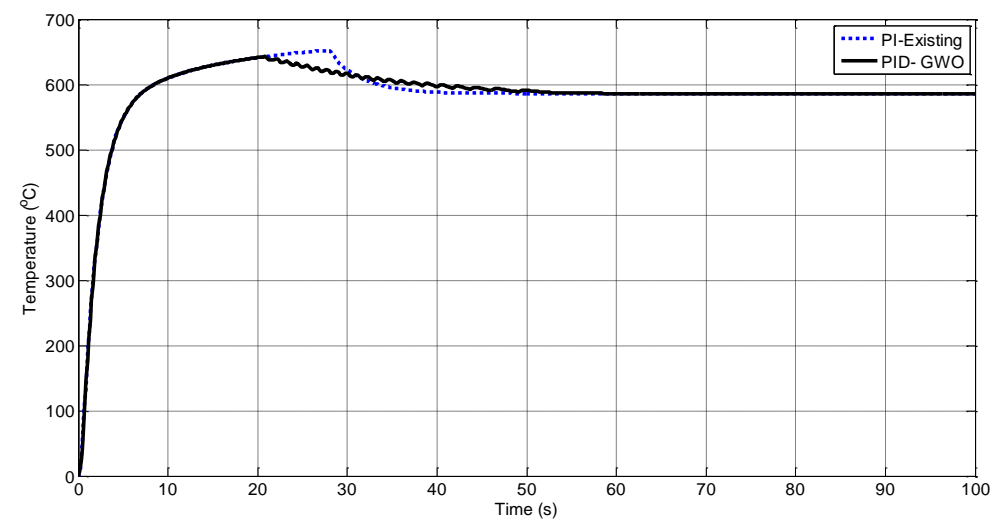

Fig (10) Exhaust temperature response for existing (PI-controller) and GWO-PID controller in case (1).

Referring to Figure (10), which represents the exhaust temperature response for GWO-PID and existing PI-controllers, the preference of the GWO-PID controller to deal with the assumed operation condition can be observed. Table [2] summarizes the more detailed results of the comparison. As can be observed from Figure (10) and Table 2, the rise time, settling time and absolute error of the GWO-PID control are shorter than the existing PI controller. However, it can also be observed that the overshoot of PI-control is more significant than that of the GWO-PID control. So, the GWO-PID controller can track the reference temperature will also; the high-temperature overshoot problem remains solved. So, using the GWO-PID controller to control the 
Hany.F. S. Abu-Seada, Grey Wolf Optimization Approach-based exhaust temperature....

temperature of the turbine increase the ability of HDGT to deal with running and operation conditions efficiently more than the existing PI-controller.

Table [2]: Comparison between GWO-PID and Existing PI-controllers case (1).

\begin{tabular}{|c|c|c|}
\hline $\begin{array}{c}\text { Max value of temperature } \\
\text { (max overshoot) }\end{array}$ & $\begin{array}{c}642^{\circ} \mathrm{C} \\
(9.6 \%)\end{array}$ & $\begin{array}{c}652^{\circ} \mathrm{C} \\
(11 \%)\end{array}$ \\
\hline $\begin{array}{c}\text { Time to start control } \\
\text { action (rise time) }\end{array}$ & $20.9 \mathrm{sec}$ & $28.3 \mathrm{sec}$ \\
\hline $\begin{array}{c}\text { Time to track the } \\
\text { temperature to steady } \\
\text { state. }\end{array}$ & $38 \mathrm{sec}$ & $44 \mathrm{sec}$ \\
\hline
\end{tabular}

Also, referring to the mechanism of GWO-PID and existing PI-Controllers to control this temperature variation which represented in Figure $(11,12)$ by zooming the time interval from the second 25 to the second 30 of the previous curves many additional advantages are obtained. Angle of decay for the temperature curve to reach the steady-state for the existing PI-controller is sharper than GWO-PID controller which give an impetration that GWO-PID is more stable and smoother to deal with disturbances and running condition. That advantage is beneficial in the case of dealing with temperatures and materials.

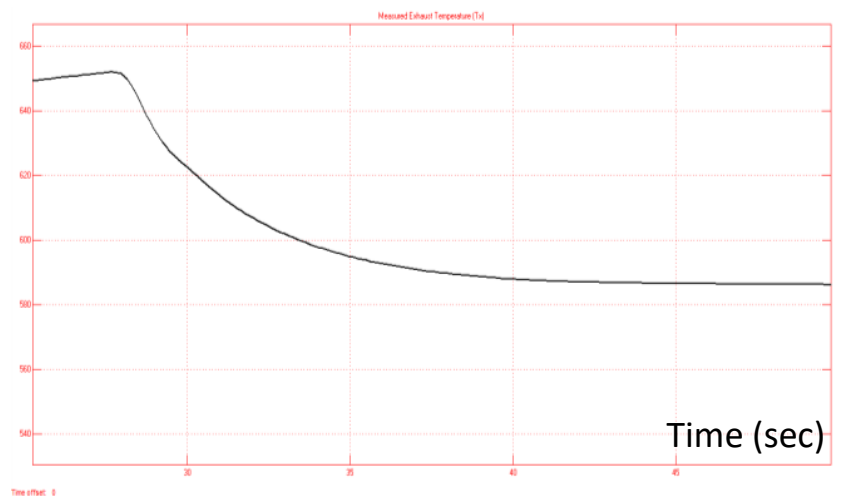

Fig (11) Exhaust temperature response for existing (PI-controller).

In Fig (12), which represents the interval of leading exhaust temperature to the steady-state by the GWO-PID controller, the temperature goes to the steadystate frequently which makes a warming behavior along with the interval. In general, warming behavior is considered one of the critical heat transfer Procedures for gas turbines, particularly at startup and shut down conditions to protect the metals from cracks. The advantage of warming behavior of 
GWO-PID controller will appear clearly in the case of combined cycle when the exhaust of gas turbine will be used to increase the temperature of HRSG (Heat Recovery Steam Generator) special in the condition of bypass operation and temperature matching mode as in this case the interval time will be longer and the benefit of warming behavior besides the IGV (inlet guide vane) control system will be sufficient.

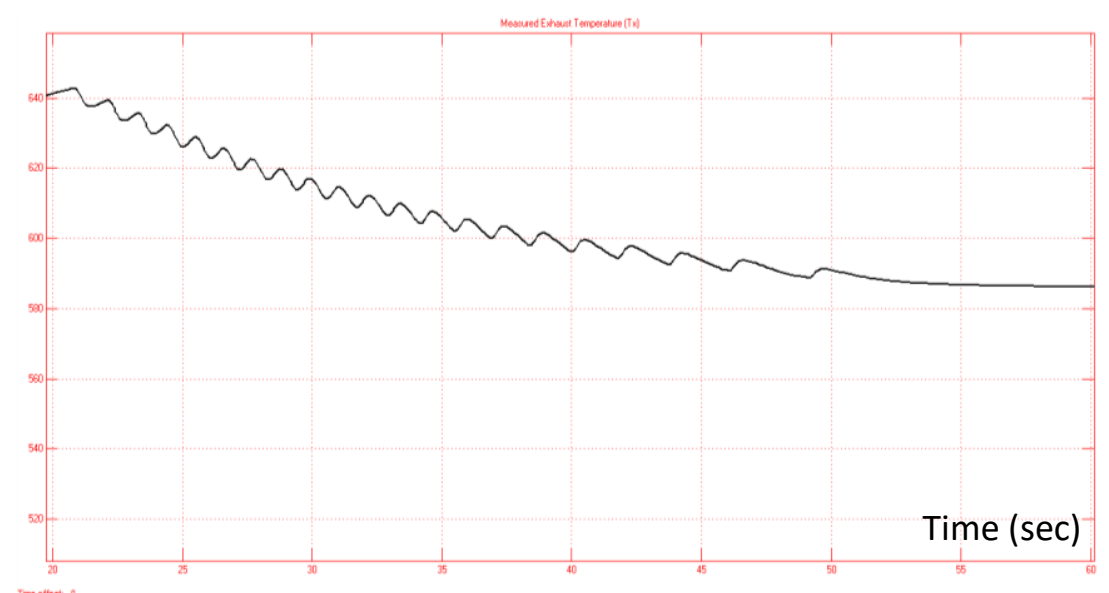

Fig (12) Exhaust temperature response for (GWO-PID controller).

\subsection{CASE (2) Variable Sequential Loading Effect}

In this case a variable sequential loading for the turbine is assumed which has the following sequence:

1- Increase from $100 \%$ of the rated MW to $120 \%$ at $10 \mathrm{sec}$ then constant for 20 sec.

2- Decay from $120 \%$ to $110 \%$ at 10 sec.

3 - Increase from $110 \%$ to $130 \%$ at $10 \mathrm{sec}$.

4- Decay from $130 \%$ to $110 \%$ at 30 sec.

Fig (14) and Table [3] show the comparison between the behavior of GWOPID and existing temperature control system (PI controller) of HDGT as the load of the turbine will change by the previous rate of MW values according to the power network load and frequency changes. 
Hany.F. S. Abu-Seada, Grey Wolf Optimization Approach-based exhaust temperature....

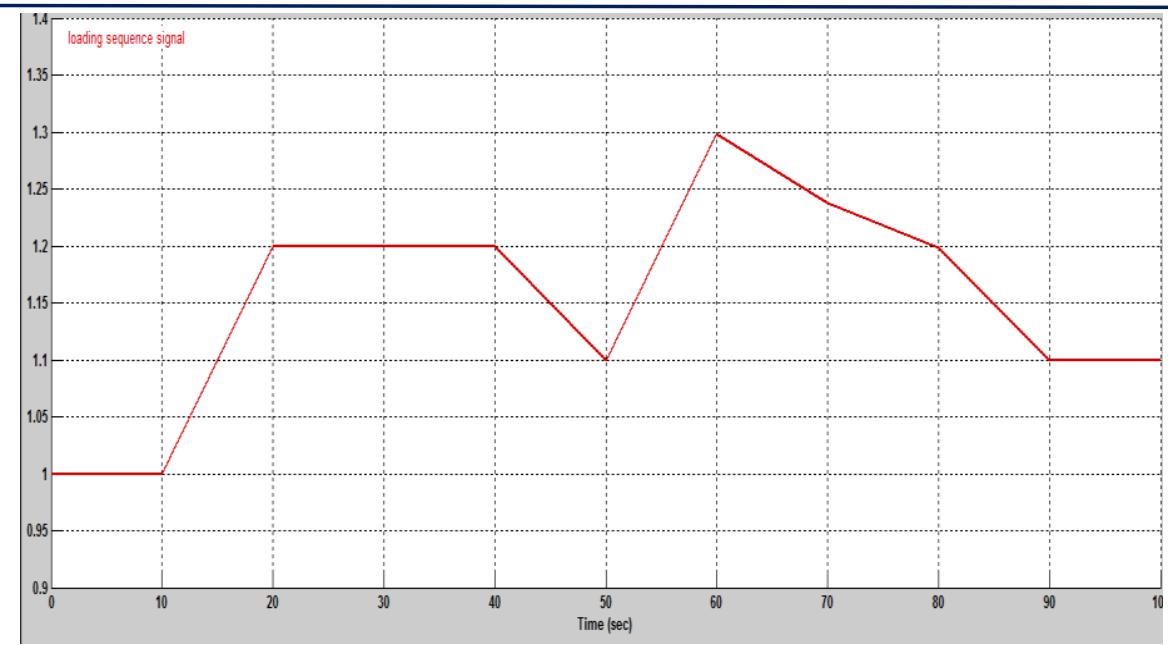

Fig (13) loading Sequence Signal

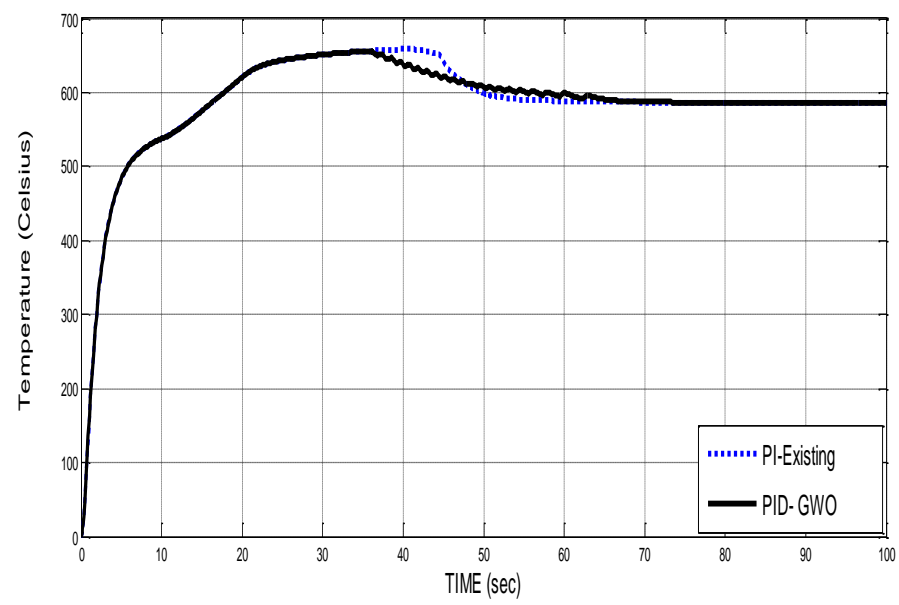

Fig (14) Exhaust temperature response for existing (PI-controller) and GWO-PID controller in case (2).

Table [3] Comparison between GWO-PID and Existing PI-controllers case (2)

\begin{tabular}{|c|c|c|}
\hline & GWO-PID controller & Existing PI-controller \\
\hline $\begin{array}{c}\text { Max value of temperature } \\
\text { (max overshoot) }\end{array}$ & $\begin{array}{c}656^{\circ} \mathrm{C} \\
(11.6 \%)\end{array}$ & $\begin{array}{c}659^{\circ} \mathrm{C} \\
(12.5 \%)\end{array}$ \\
\hline $\begin{array}{c}\text { Time to start control } \\
\text { action (rise time) }\end{array}$ & $35.6 \mathrm{sec}$ & $40.7 \mathrm{sec}$ \\
\hline $\begin{array}{c}\text { Time to track the } \\
\text { temperature to steady } \\
\text { state. }\end{array}$ & $54 \mathrm{sec}$ & $60 \mathrm{sec}$ \\
\hline
\end{tabular}




\section{Conclusion}

The paper shows a new strategy in optimizing the PID controller parameters to control the system of exhaust temperature of a $265 \mathrm{MW}$ simple cycle HDGT single-shaft gas turbine. Results have shown that although the proposed GWOPID controller deal with ITSE, ISE, ITAE and IAE performance criteria where, (includes Integral time absolute error (ITAE), Integral square error (ISE), Integral time square error (ITSE) and Integral absolute error (IAE)), it can produce system responses at a little rise time, settling time and absolute error as well as coping with the variation in ambient temperature suitable more than the existing PI-controller as a temperature control system.

A suitable choice of PID-controller's parameters KP, KI, KD values can simultaneously maintain reasonably small values of all transient response characteristics including the rise time, settling time and absolute error, as well as maximum overshoot. This gets the opportunity to increase the service life of the turbine, as it makes it possible to increase the loading on the same turbine in the future and raise the value of the energy generated from it.

\section{References}

[1] Mohamed M. Ismail, M. A. Moustafa Hassan " Modeling and Control of Combined Cycle Gas Turbines Using Rowen's and Vournas's Models" International Review on Modelling and Simulations (I.RE.MO.S.), Vol. 6, N. 3ISSN 1974-9821. June 2013

[2] Thamir Khalil, Mohamed Kamil,wadhah Hussein, Ahmed Tawfeeq, Firdaus basrawi "Study of The Performance of The Gas Turbine Power Plants From The Simple To Complex Cycle", Journal of Advanced Research in Fluid Mechanics and Thermal Sciences, Volume 57, Issue 2 (2019) 228-250.

[3] W. I. Rowen, "Simplified mathematical representations of heavy-duty gas turbines", ASME J. Eng. Power, Vol. 105 ,pp. 865-869, 1983.

[4] M. Basso, L. Giarre, S. Groppi, and G. Zappa, "NARX Models of an Industrial Power Plant Gas Turbine", IEEE Transactions on Control Systems Technology,2004.

[5] J. H. Kim, T. W. Song, T. S. Kim, and S. T. Ro, "Model development and simulation of transient behavior of heavy-duty gas turbines," ASME J. Eng. Gas Turbines and Power, vol. 123, pp. 589-594, 2001

[6] J. C. Mantzaris, M. E. Karystianos, C. D. Vournas, "Comparison of Gas Turbine and Combined Cycle Models for System Stability Studies", 2010

[7] Engineer / Hany Emam Mostafa Abdelwahab " Modeling and Control of Combined cycle power plant" faculty of engineering, Cairo university, Giza, Egypt,2010.

[8] J. C. Mantzaris, M. E. Karystianos, C. D. Vournas, "Comparison of Gas Turbine and Combined Cycle Models for System Stability Studies", MedPower Conference, Thessaloniki, 2008. 
Hany.F. S. Abu-Seada, Grey Wolf Optimization Approach-based exhaust temperature....

[9] G. Lalor and M. O'Malley, "Frequency Control on an Island Power System with Increasing Proportions of Combined Cycle Gas Turbines," in Proc. IEEE Powertech Conf., Bologna, Italy, Jun. 2003

[10] Gillian Lalor, Julia Ritchie, Damian Flynn, and Mark J. O’Malley, “The Impact of Combined-Cycle Gas Turbine Short-Term Dynamics on Frequency Control", IEEE Trans. on Power Syst., Vol. 20, No. 3, August 2005.

[11] Soon Kiat Yee, Jovica V. Milanovic', and F. Michael Hughes, "Overview and Comparative Analysis of Gas Turbine Models for System Stability Studies" IEEE Trans. Power Syst., Vol. 23, No. 1, February 2008

[12] P. P. Walsh and P. Fletcher, Gas Turbine Performance, 2nd ed. Oxford, U.K.: Blackwell Science, 2004.

[13] M. R. Bank Tavakoli, B. Vahidi, and W. Gawlik, "An Educational Guide to Extract the Parameters of Heavy-Duty Gas Turbines Model in Dynamic Studies Based on Operational Data", IEEE Trans. Power Syst., Vol. 24, No. 3, August 2009.

[14] Siemens AG, Power Generation Group, "Siemens Gas Turbines Manuals", Model V94.3A (SGT5-4000F), Windows Turbine-Generator Analysis Systems, "WIN- TS".

[15] Ali Marzoughi, Hazlina Selamat, Mohd Fua'ad Rahmat and Herlina Abdul Rahim "Optimized proportional integral derivative (PID) controller for the exhaust temperature control of a gas turbine system using particle swarm optimization" International Journal of the Physical Sciences Vol. 7(5), pp. 720 729, 30 January 2012.

[16] N. E. Y. Kouba, M. Menaa, M. Hasni, and M. Boudour, "LFC enhancement concerning large wind power integration using new optimized PID controller and RFBs," IET Gener., Transmiss. Distrib., vol. 10, no. 16, pp. 4065-4077, 2016.

[17] Mohammed H. Qais, Hany M. Hasanien, And Saad Alghuwainem "A Grey Wolf Optimizer for Optimum Parameters of Multiple PI Controllers of a GridConnected PMSG Driven by Variable Speed Wind Turbine ", College of Engineering Research Center, King Saud University, Riyadh, Saudi Arabia, August 3, 2018 


\section{التحكم في درجه حرارة عادم تربينات القوى الغازيه إستنادا لمحاكاه نهج الأنساب الرماديه في ذلتك}

تعد التوربينات الغازية واحدة من أهم تقنيات توليد الطاقة في البلدان خاصة مع موارد

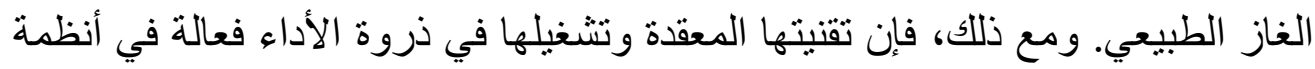

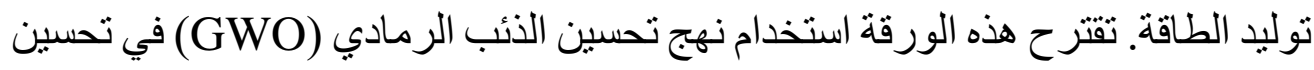
معاملات وحدة التحكم التفاضليه المتكاملة النسبية (PID) باستخدام برنامج (معمل

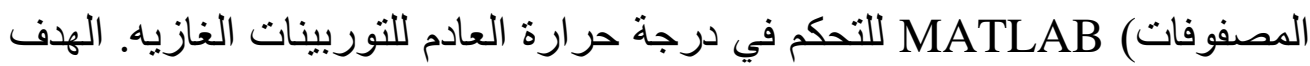
الرئيسي هو الحفاظ على سلوك تشغيل التربينات عند الأداء الأمثل. تظهر النتائج المحققة

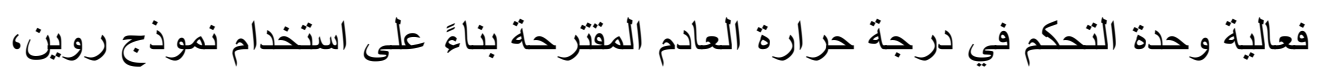
و هو النهج الواضح لتوربين الغاز.

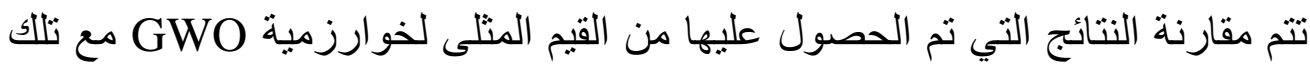

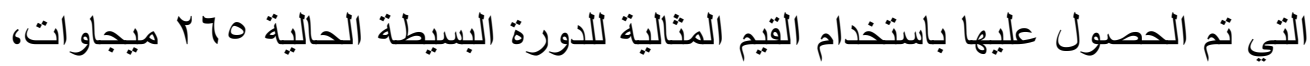

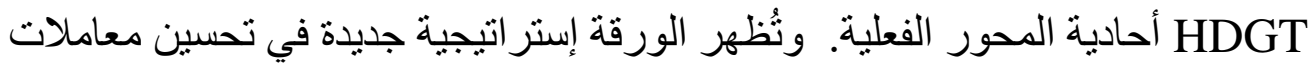
وحدة التحكم PID للتحكم في نظام درجة حرارة العادم لتربينات غاز أحادي المحور

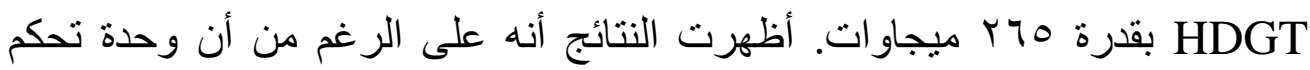

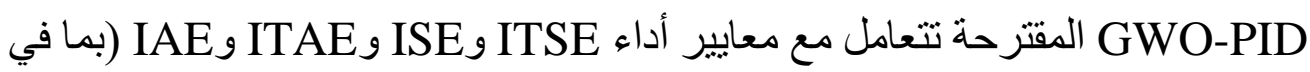

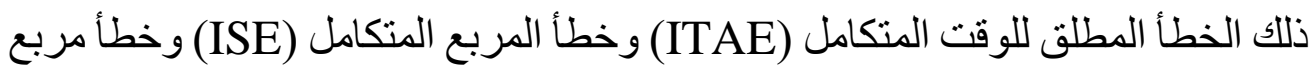
الوقت المتكامل (ITSE) وIntegral الخطأ المطلق (IAE)، حيث يمكن أن ينتج

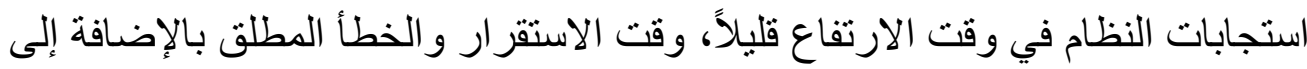
التعامل مع التباين في درجة الحرارة المحيطة المناسبة أكثر من وحدة التحكم التهاع الحالية

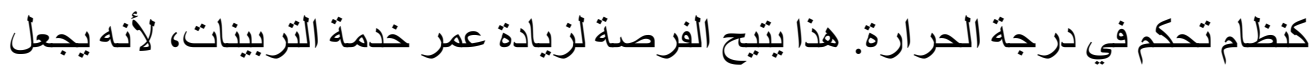

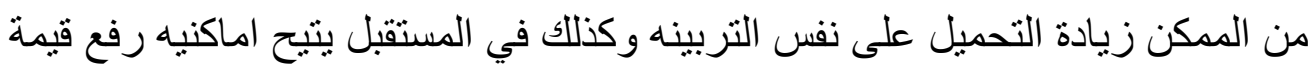
الطاقة المتولدة منه ثنطوير زلئ التصميم. 